\title{
Relations between patient personality and patients' dissatisfaction after multifocal intraocular lens implantation: clinical study based on the five factor inventory personality evaluation
}

\author{
Paulius Rudalevicius $^{1} \cdot$ Rosita Lekaviciene ${ }^{2} \cdot$ Gerd U. Auffarth $^{3} \cdot$ Rasa Liutkeviciene $^{1,4} \cdot$ Vytautas Jasinskas $^{1}$
}

Received: 12 November 2018 / Revised: 14 April 2019 / Accepted: 22 August 2019 / Published online: 20 September 2019

(c) The Author(s), under exclusive licence to The Royal College of Ophthalmologists 2019

\begin{abstract}
To assess the level of visual function and the influence of personality traits on patients' (pts) satisfaction with the visual function following the four different MIOL implantation.

Methods We evaluated the visual outcomes over a 6 months follow-up period after cataract surgery with bilateral implantation of four different multifocal IOLs. The spectacle independence, photic phenomena, the influence of personality traits on patients' satisfaction with the visual function were assessed.

Results A total of 170 eyes of 85 pts were included. There was no statistically significant difference in UDVA ( $F=1.6 p=$ $0.177)$ and CNVA $(F=1.2 p=0.30)$ between the groups 6 months after the surgery. The ReSTOR group had a worse CDVA than the M-flex $(p=0.019)$ and TECNIS $(p=0.005)$ groups. The ReSTOR and AT.LISAtri groups had a statistically significantly better UNVA than the M-flex $(p=0.020$ and $p=0.013)$ and TECNIS groups $(p=0.001$ both). The independence on spectacles for near distance was from 71.8\% (in M-flex group) to 100\% (in ReSTOR). The answers of the pts with the prevailing neurotic personality type contradicted the answers given by the pts with other prevailing personality types $(p<0.01)$.

Conclusions MIOL implantation helped ensure better postoperative visual acuity, but some pts were unhappy with the postoperative outcomes. It was established that the subjective satisfaction or dissatisfaction of patients after MIOL implantation is related to certain personality traits: pts with neuroticism as the dominant personality trait were least happy with the postoperative outcomes; pts with conscientiousness and agreeableness as dominant personality traits demonstrated the highest satisfaction with the postoperative outcomes.
\end{abstract}

Supplementary information The online version of this article (https:// doi.org/10.1038/s41433-019-0585-x) contains supplementary material, which is available to authorized users.

Rasa Liutkeviciene

rliutkeviciene@gmail.com

1 Department of Ophthalmology, Lithuanian University of Health Sciences, Medical Academy, Kaunas, Lithuania

2 Kaunas University of Technology, Faculty of Social Sciences, Arts and Humanities, Kaunas, Lithuania

3 Department of Ophthalmology, University of Heidelberg, Heidelberg, Germany

4 Department of Ophthalmology, Neuroscience Institute, Ophthalmology laboratory, Lithuanian University of Health Sciences, Medical Academy, Kaunas, Lithuania

\section{Introduction}

Cataract surgery with implantation of a monofocal intraocular lens (IOL) allows only for correction using a fixed focal length and patients remain dependent on spectacles [1-3]. An alternative treatment is the implantation of multifocal IOLs (MIOLs), which give a more acceptable range of near through distance vision [4-7]. MIOLs significantly reduce spectacle dependence, but some patients report poor vision quality under certain conditions [8-10]. Usually, the reason for dissatisfaction can be identified and removed (with the help of capsulotomy or by correcting postoperative ametrophy) [10]. Cases of dissatisfaction with the resulting photic phenomena that have no objective reason to occur are more difficult to eliminate and can be related to certain personality traits of the patient $[11,12]$. Psychologists agree that personality may play a role in the different perception of one's health condition and the surrounding 
environment [13]. American scientist Lew Goldberg coined the Five Factor Inventory scale (FFI), which was further advanced by a number of other scientists who used it in empirical studies. The scale is a well-known practical method used to assess personality traits [14-16]. With the help of the scale, personality can be assessed in terms of several different dimensions, i.e., extraversion, consciousness, agreeableness, neuroticism and openness to experience $[13,17]$. Personality traits are thought to be relatively stable. They determine the individual's emotional and cognitive style [18], behaviour type and reaction to the surrounding environment, and influence patient health [1921]. Compared with other instruments, the FFI scale is shorter and takes little time to fill out (3-5 min). In addition, it has been validated and can be used free of charge, so it is a very convenient tool to use in clinical practice [22-24]. Literature sources say that patient personality may influence their assessment of the visual function after the MIOL implantation, but the researchers had previously not used psychological tests to establish respective personality traits, therefore, this information is of purely hypothetical nature and is based on personal assumptions [11, 12]. The purpose of this research is to identify the relationship between the respective personality dimensions and the patient's assessment of their visual function after the implantation of MIOL, and to identify the personality traits that should play a significant role in deciding whether or not to select a patient for an MIOL implantation.

\section{Research material and methods}

The study was performed at the Department of Ophthalmology, Medical Academy, Lithuanian University of Health Sciences, with the permission of Kaunas Regional Bioethics Committee (No BE-2-47).

The list of selection criteria for the research subjects was drafted with the aim to eliminate the factors that might have a negative effect on the postoperative quality of vision. The following patient exclusion criteria were applied: (1) accompanying ocular diseases that might have a negative effect on the postoperative visual acuity; (2) previous ocular surgeries; (3) intensive lens opacification hampering the optical coherence biometry; (4) only one seeing eye; (5) preoperative astigmatism of more than 1.25 dioptre (D); (6) systemic diseases that might have a negative effect on visual acuity; (7) use of medication that can cause vision problems as a side effect; (8) mental illness; (9) younger than 18 years of age.

The ophthalmological study involved 85 patients who underwent a bilateral implantation of MIOL. Before the implantation, different MIOL alternatives and the possibility to have monofocal IOLs implanted were discussed with the patient. Surgical methods and the postoperative follow- up were also discussed. Patients were informed about the photic phenomena that might occur as a side effect of MIOL implantation. Patients agreed to have the same type of MIOL implanted into the other eye within 4 weeks after the first surgery. All the patients were divided into four groups according to the type of MIOL implanted. During the study they underwent bilateral implantation of the Rayner M-flex 630F (M-flex), the TECNIS ZMBOO (TECNIS), the AcrySofReSTOR (ReSTOR) or the AT.LISAtri 839 MP (AT.LISAtri) MIOLs, respectively. The implanted MIOLs differed in terms of their optic design, haptic design, and material from which they were produced. Characteristics of the implanted MIOLs are presented in Supplementary material.

\section{Preoperative examination methodology}

All patients had a full preoperative ocular examination. The uncorrected and best-corrected distance visual acuity assessment at $4 \mathrm{~m}$ was done with $\log$ MAR units under photopic conditions. Slit lamp biomicroscopy was performed. The $+90 \mathrm{D}$ double-aspheric fundus examination lens was used to examine the back segment of the eye. Any eye lens opacification was considered as a cataract. Biometry was done by partial coherence interferometry (IOL Master, Carl Zeiss Meditec). The biometric data obtained were used to select the right MIOL power and to define the level of corneal astigmatism.

\section{Surgical methods}

The same surgical method was used for all the patients in the study, i.e. extracapsular cataract extraction using the phacoemulsification method with the help of the Infinity vision system (Alcon Infiniti ${ }^{\circledR}$, Fort Worth, USA). In-thebag implantation of MIOLs was performed. The patients had their second eye operated on within 7-30 days after the first surgery.

\section{Postoperative research methodology}

Postoperative ophthalmological examination included distance visual acuity assessment at $4 \mathrm{~m}$ and at $40 \mathrm{~cm}$, including ocular biomicroscopy. Visual acuity assessment with $\log$ MAR units was done at 6 months after the second eye surgery. The uncorrected distance visual acuity (UDVA), the corrected distance visual acuity (CDVA), the uncorrected near visual acuity (UNVA) and the corrected near visual acuity (CNVA) were assessed. Monocular visual acuity assessment was performed.

At 6 months postoperatively and later during the followup patients filled out a questionnaire on vision quality and the FFI questionnaire. 
The questionnaire on vision quality included 12 questions related to the frequency of photic phenomena (glare and halos); spectacle dependence for far and near vision; and satisfaction with the quality of vision after the MIOL implantation. Glare was explained as increased luminance. Halos were explained as light rings around light sources.

The FFI included a set of 25-item bipolar adjective scales with five items per each personality dimension. The research subjects were asked to rate each item on a seven-point scale ranging from 1 to 7 . Each personality dimension was assessed separately by adding the scores given by the research subjects to different items, which allowed the prevailing personality traits of the patient (24) to be established. Different scientists give different detailed descriptions of the personality traits. For the purpose of this article, the description of the Five Factor Inventory personality traits developed by Žukauskienė and Barkauskienè was used [25]:

(1) Extraversion. It shows the level of an individual's sociability, i.e. their willingness to communicate with others. Extraverts are optimists, friendly, assertive and active.

(2) Conscientiousness. This personality dimension exhibits a tendency to plan, organise, set objectives and achieve goals. It is related to academic and educational achievement and is characteristic of organised, trustworthy, thoughtful, orderly and responsible individuals. The drawback of these individuals is excessive scrupulousness and neatness.

(3) Agreeableness. This personality trait shows that a person is altruistic, emphatic, conscious and willing to help. It is characteristic of helpful, trustful, humble, emphatic, lenient and trusting individuals.

(4) Neuroticism. It shows that a person is more prone to experiencing negative emotions, i.e. fear, sadness, discontent, guilt, anger, etc. Neuroticism relates to the likelihood of being anxious, hostile, depressed, selfconscious, impulsive and vulnerable. This personality trait is characteristic of irritable, bad-tempered, and impulsive individuals.

(5) Openness to experience. This personality trait represents a higher level of imagination and curiosity, focus on inner experience, aesthetic sensitivity, strive for knowledge, and interest in the inner and outer world. This personality trait is characteristic of intellectuals, freethinkers and individuals with a higher level of imagination.

In 2004, the FFI scale was translated into the Lithuanian language (including back-translation) and validated and has been used since then in scientific research [23, 24].

\section{Statistical data analysis}

SPSS statistics software package version 17.0 was used for the statistical analysis. Calculations of the mean and standard deviation were made for every parameter. The Kolmogorov-Smirnov test was used to check adherence to the normal distribution criterion. To test the respective statistical hypotheses against the normal distribution criteria, parametric (including $t$-testing, ANOVA and Pearson's linear correlation coefficient) or non-parametric procedures were performed with the aim of defining the statistical significance of the small sample size (Mann-Whitney), including Kruskal-Wallis criteria (in the case of three or more groups), and Spearman's rank correlation coefficient to define the relationship between two variables. The $\chi^{2}$ criterion was applied to assess the correlation between qualitative features.

Repeated ANOVA measures were used to compare preoperative and postoperative parameters. For nonparametric analysis, the Wilcoxon rank-sum test was used to assess the statistical significance of the differences between preoperative and postoperative data.

For the purpose of parametric analysis with the aim to compare different MIOL groups, unifactor dispersion analysis (ANOVA) with post hoc Bonferroni adjustment was used. In cases when it was impossible to perform parametric analysis, the Kruskal-Wallis test was used to compare different MIOL groups, and for post hoc analysis, the Mann-Whitney test with the Bonferroni adjustment was used. A $p$-value of $<0.05$ was considered significant.

\section{Results}

The study involved 170 eyes of 85 patients. Patient characteristics are presented in Supplementary material. There were no differences in gender or age among the research subjects in different MIOL groups.

During the study there were no major intraoperative complications, the postoperative period went smoothly and no MIOL was explanted. All patients completed all of the follow-up ophthalmologic measurements and all patients filled out questionnaires.

Preoperative and postoperative visual acuity outcomes at 6 months are presented in Supplementary material. No statistically significant differences between groups in preoperative UDVA $(F=1.27 p=0.258)$ were observed.

Postoperatively, all four groups had better UDVA and CDVA than preoperatively (repeated measures ANOVA, $p<$ 0.01 all). At 6 months there were no differences between groups in UDVA $(F=1.6 p=0.177)$ and CNVA $(F=1.2$ $p=0.30$ ). However, the ReSTOR group had a worse CDVA than the M-flex $(p=0.019)$ and TECNIS 
$(p=0.005)$ groups. The ReSTOR and AT.LISAtri groups had a statistically significantly better UNVA than the M-flex $(p=0.020$ and $p=0.013)$ and TECNIS groups $(p=$ 0.001 both).

Preoperative corneal astigmatism was $0.62 \pm 0.29$ (0.1-1.25 interval), at 6 months postoperatively it was $0.53 \pm 0.27(0.0-1.17$ interval $)$ and there was no statistically significant difference between the groups $(F=1.7 p=$ $0.167)$. At 6 months, there was no correlation between UDVA and corneal astigmatism (Pearson's $r=0.02 p=$ 0.83 ). However, there was a correlation between corneal astigmatism and UNVA $(r=0.15 p=0.049)$.

The analysis of answers to the questionnaire on the quality of vision showed that glare and halo symptoms during daytime and in dim light or at night differed depending on the type of implanted MIOL (Fig. 1). Patients with ReSTOR (10\%) and AT.LISAtri (40\%) IOLs reported the smallest incidence of occasional glare during daytime. As regards the other two groups, $8 \%$ of the patients with TECNIS IOLs and $16 \%$ of the patients with M-flex IOLs implanted indicated that they suffer from glare all the time. Of the patients implanted with ReSTOR IOLs, 50\% said they see additional glare occasionally in dim light or at night. However, one fourth $(25 \%)$ of the patients with TECNIS IOLs and one third of the patients with AT.LISAtri or M-flex IOLs reported a constant glare. Only $20 \%$ of them indicated that they see occasional halo, while another $10 \%$ said they see constant halo. Constant halo symptoms were reported by approximately half of the patients with the AT.LISAtri, TECNIS and M-flex IOLs implanted (Fig. 1).

There were significant differences in patient opinion about the quality of vision in terms of glare symptoms (Question 4), use of mobile phone (Question 7) and spectacle dependence for near distance (Figs. 2 and 3). Patients with the M-flex (27\% of the patients reported occasional glare, 22\% reported constant glare) and TECNIS (67\% reported occasional glare) IOLs implanted suffered from glare symptoms most. At the same time, only about a quarter $(27 \%)$ of the patients with the AT.LISAtri IOLs said they see occasional glare. The ReSTOR group gave the best assessment of the quality of their vision, as only $10 \%$ of the group reported occasional glare (Fig. 2).

The TECNIS (8\% could not see well, 33\% saw neither well nor poorly) and M-flex groups (36\% saw neither well nor poorly) reported major difficulties with the use of mobile phones. At the same time, almost all the patients in the ReSTOR group (90\%) and AT.LISAtri group (100\%) were able to see the display on their mobile phone well $\left(\chi^{2}=28.8\right.$ $\mathrm{df}=6 p<0.001)$.

The patients with the ReSTOR IOLs implanted reported total spectacle independence for near vision, while other groups reported spectacle dependence, which varied from
Do you see glare during day time?

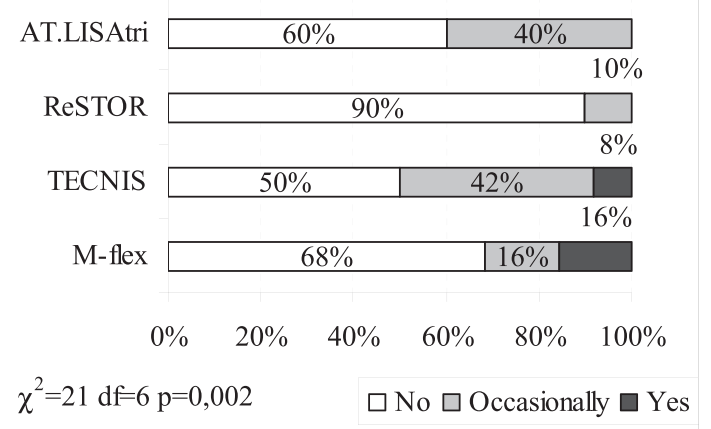

Do you see glare during night time?

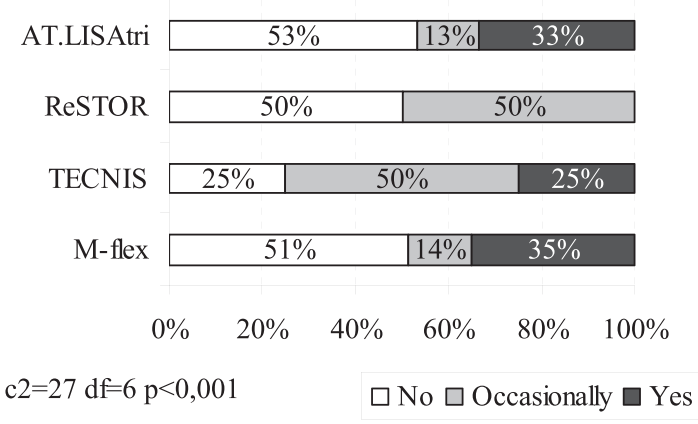

Do you see halo around lights?

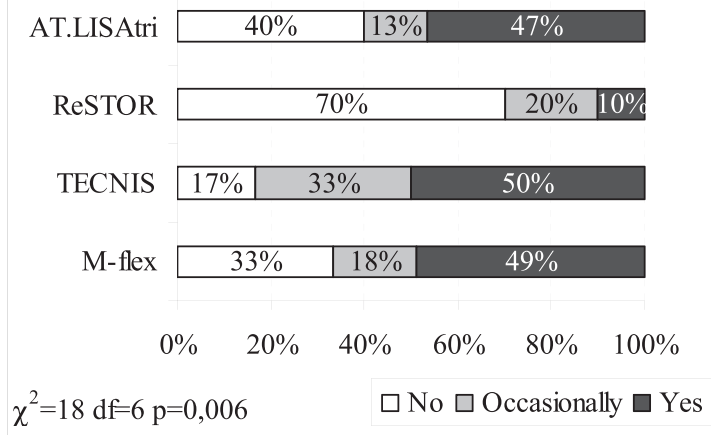

Fig. 1 Glare during day time and at night time and halo around lights dependence on the type of implanted MIOL

$7 \%$ in the AT.LISAtri group to $9 \%$ and $10 \%$ in the TECNIS and M-flex groups respectively (Fig. 3).

Having considered personality dimensions it was established that openness to experience was more characteristic of male rather than female individuals-chance correlation $(C C)=1.11$ (95\% PI 1.02-1.21; $p=0.017)$, however neuroticism was more characteristic of females $(\mathrm{CC}=0.93 ; 95 \%$ 
PI $0.87-0.99 ; p=0.028)$. The personality type of the research subjects was not related to their age. Neuroticism had a strong negative correlation with conscientiousness $(r=$ -61), agreeableness $(r=-0.72)$ and a weaker one with extraversion $(r=-0.39)$ (Table 1$)$.

The answers of the patients with the prevailing neurotic personality type contradicted the answers given by the patients with other prevailing personality types. The neurotic personalities mostly tended to give negative answers to questions 10, 11 and 12 about surgery outcomes, i.e. they reported a higher incidence of glare, they had more difficulty reading text on their mobile phone display and tended to use spectacles for near and far distance more often (Table 2).

\section{Discussion}

In the case of cataract surgery, MIOLs have been providing visual rehabilitation for far and near visual acuity for several decades already [26]. The main goal of implanting MIOLs

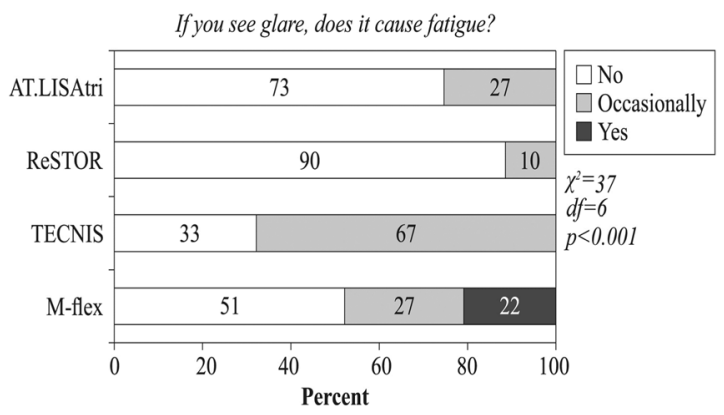

Fig. 2 Fatigue dependence on the type of implanted MIOL

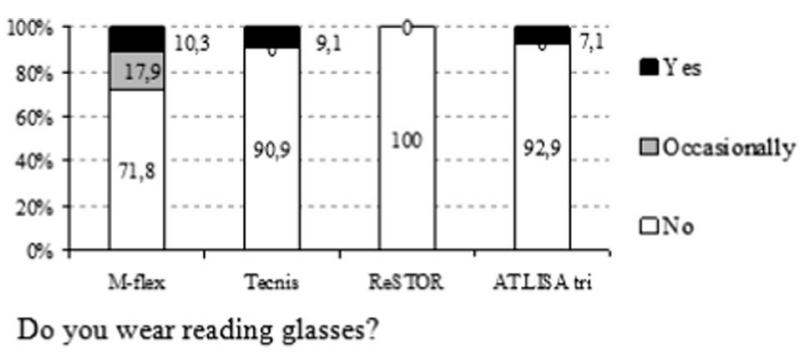

Fig. 3 Reading glasses usage dependence on the type of implanted MIOL is to provide the best levels of spectacle independence [27]. MIOLs supplied by different producers differ in terms of their optic design, material from which they are produced, sphericity and the near addition power required [28]. The optic design of these lenses allows the light beam that is reflected from one and the same object to reach the eye and penetrate the IOL through several different optic zones to create two (or three) images at a time with one of them being clear and the other blurred [29]. Despite the fact that the MIOL implantation results in good visual acuity outcomes at far and near distance, some patients are only moderately satisfied with the quality of their postoperative visual function $[10,28]$. When there is no objective reason for the dissatisfaction, study reports point to the feasible influence of the patient's personality on the way they perceive their visual function, but no exhaustive tests to establish the prevailing personality traits of the patient are performed. No scientific literature analysing the relationship between the respective personality dimensions and visual function outcomes after MIOL implantation was found. This clinical study assessed the relationship between different personality traits and subjective assessments of visual function after MIOL implantation. The fact that some patients who demonstrated good postoperative vision were unhappy with their visual function encouraged performing the respective psychological survey.

The research subjects were selected with the aim of eliminating the factors that might have a negative effect on the postoperative quality of vision. Changes in ocular structure and visual function resulting from traumas, previous surgery or illness were attributed to negative factors. Patients were checked for systemic diseases that could have a negative effect on their vision or mental condition. Researchers agree that corneal astigmatism hampers visual acuity and may cause photic phenomena [30]. The inclusion criteria in this study were not to exceed a corneal astigmatism of $1.25 \mathrm{D}$. Optical coherence biometry was performed, because the system itself is error-free and constitutes the most exact method of identifying the spherical power of the MIOL. There were no major intraoperative complications during the study and the postoperative period went smoothly. After the cataract extraction and MIOL implantation, all four groups had a significantly better UDVA and CDVA than preoperatively. There was no
Table 1 Internal correlation between personality dimensions (Spearman correlation coefficient)

\begin{tabular}{lcccc}
\hline & Extraversion & Conscientiousness & Agreeableness & Neuroticism \\
\hline Extraversion & 1 & & & \\
Conscientiousness & $0.34 * *$ & 1 & 1 & \\
Agreeableness & $0.54^{* *}$ & $0.62^{* *}$ & $-0.72^{* *}$ & 1 \\
Neuroticism & $-0.39 * *$ & $-0.61^{* *}$ & $0.17^{*}$ & $-0.23^{* *}$ \\
Openness to experience & $0.22^{* *}$ & 0.11 & \\
\hline
\end{tabular}

$* p<0.05 ; * * p<0.01$ 
Table 2 Correlation (Spearman) between personality type (according to FFI) and answers to the questionnaire

\begin{tabular}{|c|c|c|c|c|c|}
\hline Questionnaire questions & Extraversion & Conscientiousness & Agreeableness & Neuroticism & $\begin{array}{l}\text { Openness to } \\
\text { experience }\end{array}$ \\
\hline $\begin{array}{l}\text { 1. Do you see glare during daytime? } \\
\text { (No, occasionally, yes) }\end{array}$ & -0.13 & $-0.32 * *$ & $-0.15^{*}$ & $0.20 * *$ & -0.08 \\
\hline $\begin{array}{l}\text { 2. Do you see glare in dim light or at night? } \\
\text { (No, occasionally, yes) }\end{array}$ & -0.11 & $-0.28 * *$ & $-0.15 *$ & 0.14 & -0.00 \\
\hline $\begin{array}{l}\text { 3. Do you see halo in dim light or at night? } \\
\text { (No, occasionally, yes) }\end{array}$ & -0.07 & $-0.17 *$ & $-0.18 *$ & 0.14 & -0.04 \\
\hline $\begin{array}{l}\text { 4. If you see glare, does it cause fatigue? } \\
\text { (No, occasionally, yes) }\end{array}$ & $-0.19 *$ & $-0.20 * *$ & $-0.15 *$ & $0.17 *$ & -0.08 \\
\hline $\begin{array}{l}\text { 5. Do you have difficulty establishing the distance to other vehicles } \\
\text { when driving? (No, occasionally, yes) }\end{array}$ & -0.14 & $-0.28 * *$ & $-0.21 * *$ & $0.21 * *$ & -0.11 \\
\hline $\begin{array}{l}\text { 6. Do you have difficulty pouring water into a glass? } \\
\text { (No, occasionally, yes) }\end{array}$ & 0.06 & $-0.16 *$ & -0.06 & 0.13 & $-0.18 *$ \\
\hline $\begin{array}{l}\text { 7. Can you read the menu or the text on your mobile phone display } \\
\text { easily? (Difficult, Neither difficult nor easy, Easy) }\end{array}$ & -0.00 & $0.28 * *$ & 0.15 & $-0.23 * *$ & 0.12 \\
\hline 8. Do you use spectacles for far distance? (No, occasionally, yes) & 0.01 & -0.01 & -0.13 & $0.18^{*}$ & 0.09 \\
\hline 9. Do you use spectacles for near distance? (No, occasionally, yes) & -0.06 & $-0.21 * *$ & $-0.25 * *$ & $0.27 * *$ & -0.03 \\
\hline $\begin{array}{l}\text { 10. Had you known that the quality of your vision after the surgery } \\
\text { would be the way it is at the moment, would you have wanted to have } \\
\text { this IOL implanted? (No, yes) }\end{array}$ & $0.17 *$ & $0.31 * *$ & $0.20 * *$ & $-0.23 * *$ & 0.08 \\
\hline $\begin{array}{l}\text { 11. Would you recommend the implantation of this lens to your } \\
\text { immediate family? } \\
\text { (e.g. your brother, sister, spouse, etc. (No, yes) }\end{array}$ & $0.18^{*}$ & $0.32 * *$ & $0.22 * *$ & $-0.23 * *$ & 0.02 \\
\hline $\begin{array}{l}\text { 12. Are you happy with the vision outcomes? (Not happy, neither happy } \\
\text { nor unhappy, happy) }\end{array}$ & 0.11 & $0.19 *$ & $0.19 *$ & $-0.26 * *$ & -0.04 \\
\hline
\end{tabular}

-1 indicates perfect negative; $(-1,-0.75)$ strong negative; $(-0.75,-0.5)$ moderate negative; $(-0.5,-0.25)$ weak negative; $(-0.25,0.25)$ no linear association; $(0.25,0.5)$ weak positive; $(0.5,0.75)$ moderate positive; $(0.75,1)$ strong positive; and 1 perfect positive

FFI five factor inventory

$* p<0.05 ; * *<0.01$

statistical difference in UDVA between the groups, but CDVA was better in the TECNIS and M-flex groups than in the ReSTOR group. Literature also reports postoperative UDVA and CDVA that are similar to ours [31, 32]. The worse CDVA in the ReSTOR group can be explained by early neurosensory changes that were not clinically predictable before the surgery. UNVA and CNVA outcomes were good in all four groups. Other studies also report good postoperative UNVA [32]. Within the framework of our study, the ReSTOR and AT.LISAtri groups had the best UNVA, followed by the M-flex and TECNIS groups. These differences can be explained by a lower spherical equivalent in the AT.LISAtri and ReSTOR groups and supports the opinion that even a small residual ametrophia has a negative effect on UNVA with MIOLs [30]. There was no statistical difference in CNVA between the groups. All patients were spectacle independent for far distance. Other studies also report spectacle independence for far distance [26]. It was established that the refractive MIOL design (M-flex) leads to a greater need for near spectacles than the ReSTOR or AT. LISAtri MIOLs. Other authors also reported similar study outcomes [33]. Some patients reported halos while some others reported glare symptoms. It was established that diffractive trifocal MIOLs and apodized diffractive MIOLs were less often related to glare during daytime. No reliable correlation was established between the brightness of glare and the visual acuity. Other studies also report the occurrence of photic phenomena [28, 34].

The assessment of visual acuity (UDVA, CDVA, UNVA, CNVA) in relation to the MIOL type implanted showed no statistically significant correlations with personality type, which in a way confirms that the "objective" postoperative visual acuity outcomes did not depend on the prevailing personality type of a patient. Nonetheless, the subjective patient opinion about their vision depended on the prevailing personality trait. There was a correlation between neuroticism and the negative opinion of the patient about their vision after the MIOL implantation. Patients with prevailing neurotic personality traits were more prone to suffering from glare during daytime and this postoperative symptom seemed to cause them greater fatigue. They also had more difficulties establishing the distance to other vehicles, reading a menu or text on their mobile phone display. These patients tended to reply that they would have refused the MIOL implantation if they had known about the postoperative outcomes beforehand. Moreover, they used spectacles for far and near vision more often, were reluctant to recommend the MIOL implantation to their family or 
friends and expressed more dissatisfaction with the postoperative visual acuity outcomes. These correlations are in line with the traits characteristic of neurotic personalities, such as greater likelihood of being sad, angry, anxious, weepy and irritable, including greater focus on one's bodily functions, unrealistic expectations and weaker resilience to stress $[13,24,25,35,36]$. Other scientific research on the self-perception of one's health status also showed a correlation between neuroticism and a negative self-perception of one's own health [19-21]. Quite the opposite correlation was established between conscientiousness and postoperative outcomes. Conscientious patients reported fewer cases of daytime glare symptoms and the symptoms resulted in a lower fatigue level compared with other personality types. They also had fewer difficulties establishing the distance to other vehicles when driving and it was less difficult for them to read small font. Furthermore, they used spectacles for far and near vision less often. These patients tended to reply that they would recommend the MIOL implantation to their family and friends more often than patients of other personality type and expressed more satisfaction with the postoperative visual acuity outcomes. Conscientiousness is related to goal setting and self-discipline; therefore, it can have a positive effect on the selfperception of one's own health [13, 24, 25, 35]. Patients with agreeableness as the prevailing personality trait had a similar correlation with the positive postoperative outcomes to those who can boast of conscientiousness. Agreeable personalities tend to demonstrate less criticism and hostility, therefore agreeableness can be considered a positive trait in this particular case [13, 24, 25, 35]. There was no significant correlation between openness to experience and positive or negative postoperative outcomes. Patients with this personality trait prevailing were neither very happy nor very unhappy with the outcomes. This correlation was thought to be interesting in the sense that openness to experience is usually coupled with openness to novelties and curiosity (therefore, it was expected that patients with this prevailing personality trait would be more positive about their postoperative outcomes and would show more enthusiasm) [13, 24, 25, 35].

The limitations, and the strength of the study have been drawn and included into our paper. Limitations of the study: our research included a small group of patients; the study has to be continued with a larger sample size presenting further results in the future.

The strength of the study: four different types of MIOLs were included into our research; a suggestion to use a psychological questionnaire during the consultation that could help identify neurotic personalities and, by paying more attention to them, satisfaction with surgical outcomes could be increased.

\section{Conclusions}

The MIOL implantation helped ensure better postoperative visual acuity, but some patients were unhappy with the postoperative outcomes. It was established that the subjective satisfaction or dissatisfaction of patients after MIOL implantation is related to certain personality traits.

- it was established that patients with neuroticism as the dominant personality trait were least happy with the postoperative outcomes;

- patients with conscientiousness and agreeableness as dominant personality traits demonstrated the highest satisfaction with the postoperative outcomes.

Before MIOL implantation it is worth performing a validated short psychological examination of the patient with the help of the FFI scale and be cautious about MIOL implantation in patients that score is high on neurotic personality traits.

\section{Summary}

\section{What was known before}

- Relations between patient personality and patients" dissatisfaction after multifocal intraocular lens implantation: clinical study based on the Five Factor Inventory Personality Evaluation: The MIOL implantation helped ensure better postoperative visual acuity, but some patients were unhappy with the postoperative outcomes.

- It was established that the subjective satisfaction or dissatisfaction of patients after MIOL implantation is related to certain personality traits: patients with neuroticism as the dominant personality trait were least happy with the postoperative outcomes; patients with conscientiousness and agreeableness as dominant personality traits demonstrated the highest satisfaction with the postoperative outcomes.

\section{What this study adds}

- When planning to implant MIOLs, it is worth performing a psychological examination of the patient and be cautious about selecting patients that score high on neurotic personality traits.

Funding This work was funded by Lithuanian University of Health Sciences and Kaunas University of Technology. 


\section{Compliance with ethical standards}

Conflict of interest The authors declare that they have no conflict of interest.

Publisher's note Springer Nature remains neutral with regard to jurisdictional claims in published maps and institutional affiliations.

\section{References}

1. Sharma KK, Santhoshkumar P. Lens aging: effects of crystallins. Biochim Biophys Acta. 2009;1790:1095-108.

2. Becker KA, Martin M, Rabsilber TM, Entz BB, Reuland AJ, Auffarth GU. Prospective, non-randomised, long term clinical evaluation of the foldable hydrophilic single piece intraocular lens: results of Centerflex FDA study. Br J Ophthalmol. 2006;90:971-4.

3. Vilaseca M, Arjona M, Pujol J, Issolio L, Guell JL. Optical quality of foldable monofocal intraocular lenses before and after injection: comparative evaluation using a double-pass system. J Cataract Refract Surg. 2009;35:1415-23.

4. Lane SS, Morris M, Nordan L, Packer M, Tarantino N, Wallace RB III. Multifocal intraocular lenses. Ophthalmol Clin North Am. 2006;19:89-105

5. Bellucci R. Multifocal intraocular lenses. Curr Opin Ophthalmol. 2005;16:33-7.

6. Kohnen T, Allen D, Boureau C, Dublineau P, Hartmann C, Mehdorn E, Rozot P, Tassinari G. European multicenter study of the AcrySof ReSTOR apodized diffractive intraocular lens. Ophthalmology. 2006;113:578-84.

7. Alfonso JF, Puchades C, Fernandez-Vega L, Montes-Mico R, Valcarcel B, Ferrer-Blasco T. Visual acuity comparison of 2 models of bifocal aspheric intraocular lenses. J Cataract Refract Surg. 2009;35:672-6.

8. Montes -Mico R, Espana E, Bueno I, Charman WN, Menezo JL. Visual performance with multifocal intraocular lenses; mesopic contrast sensitivity under distance and near conditions. Ophthalmology. 2004;111:85-96.

9. Leyland M, Zinicola E. Multifocal versus monofocal intraocular lenses in cataract surgery; a systematic review. Ophthalmology. 2003;110:1789-98.

10. Woodward MA, Randleman JB, Stulting RD. Dissatisfaction after multifocal intraocular lens implantation. J Cataract Refract Surg. 2009;35:992-7.

11. Braga-Mele R, Chang D, Dewey S, Foster G, An Henderson B, Hill W, Hoffman R, Little B, Mamalis N, Oetting T, Serafanao D, Talley-Rostov A, Vasavada A, Yoo S. Multifocal intraocular lenses: relative indications and contraindications for implantation. J Cataract Refract Surg. 2014;40:313-22.

12. Goes FJ. Visual results following implantation of a refractive multifocal IOL in one eye and a diffractive multifocal IOL in the contralateral eye. J Refract Surg. 2008;24:300-5.

13. John OP, Srivastava S. The Big Five trait taxonomy: History, measurement, and theoretical perspective. Handbook of personality: Theory and research. 1999;4:102-38.

14. Zhang LF. Thinking styles and the Big Five personality traits. Educ Psychol 2002;22:17-31.

15. Kairys A. Didysis penketas: už ir prieš. Psichologija 2008; 37:71-84.

16. Bukšnytè-Marmienė L, Kovalčikienė K, Ciūnytė A. Didžiojo penketo asmenybès bruožų ir kognityvinio stiliaus sąsajos. Tarptautinis psichologijos žurnalas: biopsichosocialinis požiūris 2012;10:125-43.
17. McCrae RR, Terracciano A. Universal features of personality traits from the observer's perspective: data from 50 cultures. J Personal Soc Psychol 2005;88:547-61.

18. Mount MK, Barrick MR, Scullen SM, Rounols J. Higher - order dimensions of the Big Five personality traits and the big six vocational interest types. Personal Psichol 2005;58:447-78.

19. Durrett C, Trull TJ. An evaluation of evaluative personality terms: a comparison of the big seven and five-factor model in predicting psychology. Psychol Asssess 2005;17:359-68.

20. Cuijpers P, van Straten A, Donker M. Personality traits of patients with mood and anxiety disoders. Psychiatry Res 2005;133:229-37.

21. Weiss A, Costa PT. Domain and facet personality predictors of allcause mortality Medicare patients aged 65 to 100. Psychom Med 2005;67:724-33.

22. Goldberg LR. A broad-bandwidth, public domain, personality inventory measuring the lower-level facets of several five-factor models. Personal Psychol Eur 1999;7:7-28.

23. Bunevičius A, Katkute A, Birbilaitė I. Validity of Lithuanian version of the Modern Personality Assessment based on the BigFive personality dimensions questionnare. Biol Psychiatry Psychopharmacol 2008;10:27-30.

24. Bunevičius A. Didžiojo penketo asmenybès dimensijos. Biol Psychiatry Psychopharmacol 2005;6-7:34.

25. Žukauskienė R, Barkauskienė R. Lietuviškosios NEO PI-R versijos psicho-metriniai rodikliai. Psichologija 2006;33:7-21.

26. Agresta B, Knorz MC, Kohnen T, Donatti C, Jackson D. Distance and near visual acuity improvement after implantation of multifocal intraocular lenses in cataract patients with presbyopia: a systematic review. J Refract Surg. 2012;28:426-35.

27. Toto L, Falconio G, Vecchiarino L, Scorcia V, Di Nicola M, Ballone E, Mastropasqua L. Visual performance and biocompatibility of 2 multifocal diffractive IOLs; six-month comparative study. J Cataract Refract Surg. 2007;33:1419-25.

28. De Vries NE. Nuijts RMMA. Multifocal intraocular lenses in cataract surgery: literature review of benefits and side effects. J Cataract Refract Surg. 2013;39:268-78.

29. Davison JA, Simpson MJ. History and development of the apodized diffractive intraocular lens. J Cataract Refract Surg. 2006;32:849-58.

30. Hayashi K, Manabe S-i, Yoshida M, Hayashi H. Effect of astigmatism on visual acuity in eyes with diffractive multifocal intraocular lens. J Cataract Refract Surg. 2010;36:1323-9.

31. Zelichowska B, Rekas M, Stankiewicz A, Cervino A, MontesMico R. Apodized diffractive versus refractive multifocal intraocular lenses: optical and visual evaluation. J Cataract Refract Surg. 2008;34:2036-42.

32. Vingolo EM, Granga P, Iacobelli L, Grenga R. Visual acuity and contrast sensitivity; AcrySof ReSTOR apodized diffractive versus AcrySof SA60AT monofocal intraocular lenses. J Cataract Refract Surg. 2007;33:1244-7.

33. Alio JL, Grabner G, Plaza-Puche A, Rasp M, Pinero DP, Seyeddain O, Rodriguez-Prats J, Ayala MJ, Moreu R, Hohensinn M, Riha W, Dexl A. Postoperative bilateral reading performance with 4 intraocular lens models: six-months results. J Cataract Refract Surg. 2011;37:842-52.

34. Lichtinger A, Rootman DS. Intraocular lenses for presbyopia correction: past, present, and future. Curr Opin Ophthalmol. 2012;23:40-6.

35. Tabrett DR, Latham K. Adjustment to vision loss in a mixed sample of adults with established visual impairment. Investiga Ophthalmol Vis Sci. 2012;53:7227-33.

36. Suls J, Martin R. The daily lifr of the garden-variety neurotic: reactivity, stressor exposure, mood spillover, and maladaptivite coping. J Personal. 2005;73:1485-510. 